Session 1392

\title{
Assessing Women in Engineering (AWE): Assessment Results on Women Engineering Students Beliefs
}

\author{
Rose M. Marra, Cherith Moore,; Mieke Schuurman; Barbara Bogue \\ University of Missouri - Columbia / The Pennsylvania State University
}

Introduction

Women in Engineering (WIE) programs around the United States are a crucial part of our country's response to the need for more women in engineering professions ${ }^{1}$. For Women in Engineering (WIE) programs to be maximally effective, they must have access to validated assessment instruments for measuring the effectiveness of their recruitment and retention activities for women in engineering studies. Such assessment results can provide the basis for the development and revamping of effective activities designed to meet program objectives and missions.

This paper reports the development and early results of a survey undertaken as part of the National Science Foundation-funded Assessing Women in Engineering (AWE) project. The instrument is designed to measure undergraduate women students' self-efficacy in studying engineering. Self-efficacy is "belief in one's capabilities to organize and execute the sources of action necessary to manage prospective situations" ${ }^{2}$. Prior work from Blaisdell ${ }^{3}$ has shown that feelings of efficaciousness can be an important predictor in the success of women studying engineering. In our project, we developed a survey instrument designed to measure self-efficacy in engineering, feelings of inclusion and outcomes expectations, and collected responses from undergraduate women studying engineering at four institutions: Penn State University (PSU), Georgia Institute of Technology (GA Tech), University of Texas - Austin (UT Austin) and Rensselaer Polytechnic Institute (RPI).

The paper describes the development process for ensuring reliability and validity and also reports the preliminary results of the analysis to answer the following research questions.

1. Do students' feelings of self-efficacy vary from one institution to another?

2. Do students with different year-standings answer the module items differently regardless of institution?

3. At each institution, do students with different year-standings answer the module items differently? 
Background and Related Literature

This study addresses one of many assessment needs for WIE programs - assessing engineering self-efficacy of undergraduate women engineering students. In this section, we review the purposes of WIE programs, their assessment needs and review research literature on how selfefficacy is pertinent to these programs.

WIE Programs and the Need for Assessment

Many sources and historical data have shown the consistently low representation of women in undergraduate engineering curricula and in the engineering workforce. Specifically, women comprise approximately only $20 \%$ of undergraduate engineering school enrollment nationwide and only about $8.5 \%$ of the United State's engineers ${ }^{4}$. Establishing WIE programs at approximately 50 colleges and universities around the United States has been one response to this situation ${ }^{5}$. WIE programs serve many functions, but their primary responsibilities focus on recruitment of women into engineering undergraduate programs and then retention and development of those same women within their programs of study. Initially, this may sound well defined, but the ways in which WIE programs work to accomplish these outcomes vary tremendously.

WIE programs serve to both widen the pipeline for K-12 women and girls and then become a reservoir and pumping station for many of the undergraduate, graduate and sometimes women faculty in the colleges or university. Anecdotal and research results on specific programs show that WIE programs do have an impact on the goal expressed by the National Science Foundation (NSF) and other engineering and science industrial and academic leaders to broaden participation of girls and young women in engineering and technology $1,6,7,8,9$. Nonetheless, the development of effective and consistent assessment and evaluation of WIE program's activities (e.g. the recruitment and retention activities) and the overall programs themselves is still in its infancy.

Certainly there are significant externally funded assessment activities that have focused on longitudinal studies of some of the larger WIE programs at Purdue, Dartmouth and the University of Washington ${ }^{10,11}$. However, these are the exception and not the rule both in terms of funding and effort level, and the types of analysis used. Further, these efforts do not address vital assessment questions such as these: Is a particular activity meeting its recruitment or retention objectives? What impact is it having on student enrollment or persistence? Should we continue this activity or use limited resources to fund another, more effective activity? What would be more effective?

We recognize there are good reasons for the state of assessment activities in WIE programs. The Women's Experiences in College Engineering Project's (WECE) interviews with 28 WIE directors from 26 institutions provide valuable insights into WIE programs and directors that reflect on assessment and evaluation ${ }^{4,9}$. Several findings from this report are pertinent. First, not surprisingly, time is of the essence. The WIE directors described their time as generally being divided between four major activities: recruiting, retention, fundraising and advising students. Secondly, at most institutions the WIE staff is very small and fragmented. In their sample, Thompson, et $\mathrm{al}^{9}$ found that only 9 of the 28 directors interviewed indicated they had full time 
staff and it was not reported whether these were financed via "hard" or "soft" funding. Additionally, not all directors were full time on WIE.

Data from our own survey of WIE directors ${ }^{12}$ supports and expands upon Thompson et al's 9 findings. Not only are few directors full time, their support staffs are generally not full time and often there are multiple support staff, each working in some unique part-time arrangement, typically on "soft" funding. The result is that WIE staffing is fragmented, making continuity and comprehensiveness in activity execution and follow-up difficult if not impossible. Regarding assessment in particular, there is little time to devote to developing valid and reliable assessment instruments, and even if data are collected, there may not be adequate time or expertise to usefully analyze or even compare the results longitudinally.

\section{Self-efficacy and Engineering Self-Efficacy}

Self-efficacy is an extensively researched psychological construct grounded in social cognitive theory. The construct has been applied to a range of human endeavors, including educational and career choices and achievement. The research literature, which originates from the fields of social and cognitive psychology and to a lesser extent specific application areas such as science and engineering education, makes a convincing case that a strong sense of self-efficacy is integral to students' entry and persistence in engineering.

The term "self-efficacy" is often used interchangeably with several others, notably "confidence". Understanding the differences in these words is important in accurately interpreting the research literature and in developing programs or activities to influence self-efficacy, as well as accompanying assessment instruments. There are also many kinds of self-efficacy. Consider the following.

Self-efficacy, as defined by Albert Bandura ${ }^{13}$, "refers to beliefs in one's capabilities to organize and execute the courses of action required to produce given attainments" (p.3). The term "perceived self-efficacy" is often used, because the individuals who hold them subjectively develop self-beliefs. Although the idea of "general," "global." or "omnibus" self-efficacy are sometimes considered (see ${ }^{14}$ ), self-efficacy is more often discussed in terms of specific or "domain-linked" activities, such as engineering self-efficacy. Bandura ${ }^{13}$ explains that in a general measurement of self-efficacy, items are decontexutalized and cast in general terms. This is problematic because respondents are forced to guess what is being asked of them and each respondent will come to a different conclusion.

Confidence, while often used interchangeably with self-efficacy, refers only to the strength of certainty of one's beliefs, but does not require a positive outcome. A person may be absolutely confident in failure, for example ${ }^{13}$. Although the term "confidence" is not synonymous with self-efficacy, it can be understood as a component of it when expressed positively.

Since self-efficacy is task-specific, there are many different kinds of self-efficacy. Some more commonly investigated types of self-efficacy relevant to women in engineering are mathematics self-efficacy ${ }^{15}$, science self-efficacy ${ }^{16}$, academic milestones self-efficacy ${ }^{17}$, career decisionmaking self-efficacy ${ }^{18}$, career self-efficacy ${ }^{19}$ and agentic self-efficacy ${ }^{20}$. 
The influence of self-efficacy on human endeavors is far-reaching. Bandura ${ }^{13}$ claims that selfefficacy determines "the courses of action people choose to pursue, how much effort they put forth in given endeavors, how long they will persevere in the face of obstacles and failures, their resilience to adversity, whether their thought patterns are self-hindering or self-aiding, how much stress and depression they experience in coping with taxing environmental demands, and the level of accomplishments they realize." (p. 3) In fact, a substantial amount of research is available to support these claims. Most relevant to women in engineering is the prolific research on self-efficacy beliefs in relation to academic achievement (e.g. ${ }^{17}$ ) and to career choice (e.g. ${ }^{21}$ ).

Literature about the experiences of women in engineering frequently addresses self-efficacy and its related constructs (e.g. confidence, self-esteem). In terms of self-appraisal, a general pattern of loss emerges throughout the engineering education. Women enter engineering reporting high levels of self-confidence and self-esteem ${ }^{22}$. Their self-confidence declines precipitously during the first year and, although it does begin to elevate, it will never again reach the same heights ${ }^{10}$. During this time, women compare themselves unfavorably to their male peers and judge themselves more harshly than the men judge themselves ${ }^{23}$. Women are aware of this and identify low self-confidence as a major barrier to completing their engineering degree ${ }^{25}$. Women who leave engineering consistently express less confidence in their abilities than the men and women who stay, regardless of the fact that their actual performance is the same or better than their peers who do not leave ${ }^{10,26}$. The discouraging nature of low-self confidence is reflected in the fact that women faced with actually failing a course are likely to leave the engineering program altogether, while their male peers are more likely to repeat the course and continue to pursue their engineering degree ${ }^{27}$.

Note, however, that the above studies do not adhere to strict definitions of self-efficacy and are not part of the literature that specifically addresses self-efficacy in academic achievement and career/major choice. While gender differences in "confidence" are often reported ${ }^{10}$, gender differences in self-efficacy are difficult to locate in the literature on women who are already enrolled in engineering programs. In contrast to several studies that did not find gender differences for engineering self efficacy (e.g. ${ }^{28,29}$ )two studies did find some statistically significant gender differences in self-efficacy of engineering students, both in relation to participants' perceived sources of self-efficacy. Bradburn ${ }^{30}$ found differences in self-efficacy, partially due to differences in negative persuasion and anxiety signals. Differences in selfefficacy found in this study were strong enough that, when eliminated statistically, gender differences in attrition were also eliminated. Zeldin and Pajares ${ }^{31}$ also found gender differences in self-efficacy sources through their qualitative study of men and women who had entered into and continued to succeed in SMET professional careers. Narrative analysis revealed that men perceived mastery experiences as critical to their self-efficacy beliefs, while women valued verbal persuasion and vicarious experiences.

In general, studies of self-efficacy of engineering students have shown a positive correlation between self-efficacy and academic achievement in this highly selective and academically homogenous group. Studies on gender differences have focused on students enrolled in engineering at the time of the study and have sometimes declined to include male students for a basis of comparison. In our literature review efforts, we have not found any studies that have 
compared self-efficacy scores of male and female engineering students with those who have left the major and those who never entered the major. This may account for the fact that gender differences in self-efficacy for science, math, and technology are sometimes found prior to entering the major, but not among already-enrolled students. Related research does suggest that factors such as self-concept, self-esteem, and confidence may influence women to leave the engineering major (or never choose it at all), but these studies cannot be used to draw conclusions on self-efficacy per say. Research including multiple comparison groups over time would have to be conducted to clearly reveal the nature of the nexus of gender, self-efficacy, sources of self-efficacy and engineering.

Although building of self-efficacy is likely an element of many WIE activities, there are only a few programs with this mission explicitly stated. It is notable, however, that confidence and selfefficacy are closely related and that there are many programs designed to address confidence. Additionally, many WIE programs seek to enhance the sources of self-efficacy without ever mentioning an end goal improving self-efficacy. Some examples may include hands-on experiences that offer a chance for mastery experiences, role modeling and mentoring programs that provide for vicarious learning, stress reducing programming designed to address physiological responses and verbal persuasion as a likely component of most or all WIE activities. Given the prevalence of activities oriented towards improving self-efficacy, the authors, as part of an NSF-sponsored grant designed to develop assessment tools for WIE programs focused our initial assessment efforts on designing, testing and analyzing the results of an engineering self-efficacy instrument. Next, we describe our methodology for designing and implementing the self-efficacy instrument.

Methodology

Subjects

Subjects were undergraduate women studying engineering who were also participants in Women in Engineering program act ivies at the following institutions: The Pennsylvania State University, Georgia Institute of Technology, Rennselaer Polytechnic Institute and the University of Texas - Austin.

Procedures

Two hundred and two surveys were collected from women students at four WIE programs that participate in our NSF AWE grant: Penn State University (PSU), Georgia Tech (GT), University of Texas (UT) - Austin, and Rensselaer Polytechnic Institute (RPI). These four programs collectively represent a variety of private and public, years of experience for WIE directors and student body characteristics that provide a women engineering student sample that is largely representative of undergraduate women studying engineering in the United States. Subjects were recruited via email, phone and other types of written communications at each institution. In all cases, subjects were women engineering students who had some affiliation with the women in engineering program at that institution.

The student distribution per institution for those completing the instrument is shown in Table 1.

Table 1: Participants by institution and by year standing 


\begin{tabular}{|l|l|c|c|c|c|c|}
\hline \multicolumn{2}{|c|}{} & \multicolumn{4}{|c|}{ Year-standing } & \\
\hline \multicolumn{1}{|l|}{} & $\begin{array}{c}\text { First } \\
\text { year }\end{array}$ & $\begin{array}{c}\text { Second } \\
\text { year }\end{array}$ & $\begin{array}{c}\text { Third } \\
\text { year }\end{array}$ & $\begin{array}{c}\text { Fourth / } \\
\text { Fifth year }\end{array}$ & Total \\
\hline Institution & Georgia Tech University & 14 & 3 & 3 & 11 & 31 \\
& $\begin{array}{l}\text { Penn State University } \\
\text { Rensselaer Polytechnic }\end{array}$ & 25 & 13 & 16 & 23 & 77 \\
& $\begin{array}{l}\text { Institute } \\
\text { University of Texas - }\end{array}$ & 16 & 10 & 13 & 11 & 39 \\
& Austin & 63 & 34 & 45 & 55 & 50 \\
\hline
\end{tabular}

${ }^{1)} \mathrm{We}$ combined fourth and fifth year students into one group, because we would not have enough participants in the fifth year group for analyses purposes.

2) Five students did not indicate the year they were in, and were therefore excluded from further analyses

Data collection, using the same procedures, is also occurring at the University of Louisville, and the University of Arizona, however their data were not yet available to include in this paper.

\section{Instrument}

The instrument used in the study is designed to measure the self-efficacy of women studying engineering. Prior instrument development research has shown that self-efficacy is most validly measured by querying respondents about their feelings of efficaciousness in a very specific context - thus this instrument strives to measure engineering self-efficacy. To construct a selfefficacy instrument, one identifies the typical barriers that stand between the individual and her or his success in the domain. Thus, this self self-efficacy instrument is designed to identify the sources of barriers or obstacles in the task of obtaining an engineering degree and ascertain how capable a person feels in those situations. The survey, which includes items adapted from Blaisdell ${ }^{3}$ and Betz and Hackett ${ }^{21}$, was developed and pilot tested to ensure reliability and validity.

The instrument is best used as a longitudinal tool for all women engineering undergraduate students (both WIE/WISE participants and non participants) annually at the beginning of the academic year. This longitudinal data collection combined with tracking of student participation in WIE / WISE activities and tracking for retention in the engineering curriculum will allow directors / researchers to ascertain the overall impact of different levels of participation or participation in specific activities on women's self efficacy in studying engineering. Further, if such tracking and data collection is done at a national level, the women in engineering community will have data for comparisons between and among different institutions and programs nationwide.

Our construction of different scales for this instrument was based on the need to measure different types of outcomes. For instance in one set of items, we chose to use a dual scale that measures the extent to which students agree with the statement as well as their rating of the importance of the item (e.g. I feel I have a lot in common with the other people in my classes). This will allow directors/ researchers to both ascertain the student's positions on the various factors measured by the items (e.g. feelings of inclusion - see below for full list of factors) and 
how important participants judge each of those factors to be - thus providing guidance towards program development. Although "importance" could conceivably be measured for every item on the instrument, we determined that the dual scale design would be too much of a burden for respondents on all items, so for other items we chose to use simpler Likert-type scales.

Results of our validity and reliability analyses show that the 80-item survey measures several factors that are related to the concepts of self-efficacy, inclusion and outcomes expectations. These factors are expressed in modules, or groups of questions designed to measure student responses to the specific factor. The modules of items that define each of these factors are shown in Figure 1. The items use the following Likert-type answer scales.

- Modules 1,2 and 3: Students were asked to indicate the extent to which they agreed with the items on a five-point scale from strongly disagree $(=0)$, to strongly agree $(=4)$.

- Modules 4 and 5: Students were asked to indicate how confident they were on a ninepoint scale from not at all confident $(=0)$ to completely confident $(=8)$.

- Modules 6, 7, 8 and 9: Students were asked to indicate the extent to which they agreed with the items on a ten-point scale from strongly disagree $(=0)$ to strongly agree $(=9)$.

\section{Modules}

1. Confidence that women can succeed in an engineering career. ( 3 items, alpha $=.81$ )

2. Confidence in personal success in engineering curriculum. ( 5 items, alpha $=.74)$

3. Feeling of inclusion and having engineering role models $(7$ items, alpha $=.72$ )

4. Confidence in doing well in engineering major. ( 8 items, alpha $=.87)$

5. Confidence in being able to cope with difficulties. ( 6 items, alpha $=.75)$

6. Expectation that math is important for career and self worth. (3 items, alpha $=.81$ )

7. Expectation that engineering degree will result in obtaining desired lifestyle and job. (4 items, alpha $=.78$ )

8. Expectation to get fair chance in engineering job market. ( 3 items, alpha $=.80$ )

9. Expectation to be treated fairly in an engineering job and to feel part of the group. ( 3 items, alpha $=.81)$

Figure 1. Survey instrument modules.

Our statistical analyses showed acceptable Cronbach's Alpha reliability coefficients for each module; they ranged from .72 to .87 (see Figure 1). We ensured validity of our modules with several procedures, for example factor analyses to ensure construct validity and external expert reviews to ensure content validity.

Sample items from several modules are shown in Figure 2. 
Module 2: Confidence in personal success in engineering curriculum.

(strongly disagree $(=0)$, to strongly agree $(=4)$ )

I am confident that I can succeed in an engineering curriculum

Module 4: Confidence in doing well in engineering major.

(confident $(=0)$ to completely confident $(=8)$ )

Complete the math requirements for most engineering majors?

Module 6: Expectation that math is important for career and self worth.

(strongly disagree $(=0)$ to strongly agree $(=9)$ )

Doing well at math will enhance my career/job opportunities.

Module 9: Expectation to be treated fairly in an engineering job and to feel part of the group.

(strongly disagree $(=0)$ to strongly agree $(=9)$ )

I expect to be fairly rewarded for the contributions I make in engineering.

Figure 2. Sample items for selected modules.

Results

Although we are currently in the process of collecting longitudinal data, only cross-sectional results for women students studying engineering ${ }^{1}$ are available at this writing. Our results therefore focus on examining potential differences between the institutions where we collected data, as well as differences in responses between students with varying class standings (e.g. $1^{\text {st }}$ year students as compared to $4^{\text {th }}$ year students). All analyses were conducted by examining differences in responses to the modules of items as defined previously.

To analyze the data, we calculated the mean module scores for each student and conducted multivariate analysis of variance (MANOVA) with nine module scores as the dependent variables for each of the research questions.

\section{Effects of institutions}

The participating institutions in our grant were purposefully selected to represent both a variety of Women in Engineering programs (e.g. age of program, characteristics of WIE directors) as well as a variety of student populations. Therefore it is reasonable to examine the data for differences in responses from students at different institutions. The following results address the question.

1. Do students answer the module items differently at the different institutions?

We found a difference among institutions for module $6(F(3,180)=2.75, p<.05)$, which addresses "Expectation that math is important for career and self worth". Table 2 shows the averages and standard deviations for the different institutions for this module.

Table 2: Averages and standard deviations for module 6: "Expectation that math is important for career and self worth."

\footnotetext{
${ }^{1}$ Because this was the first data collection was designed to validate the self-efficacy instrument, and because we designed the instrument to focus on barriers for women engineering students, we limited data collection to women. Subsequent iterations will be used with men and women and we will reanalyze our items for reliability at that time.
} 


\begin{tabular}{|l|c|c|}
\hline Institution & Mean $^{1)}$ & SD \\
\hline Georgia Tech University $(\mathrm{N}=29)$ & 7.12 & .97 \\
\hline Penn State University $(\mathrm{N}=68)$ & 6.45 & 1.17 \\
\hline Rensselaer Polytechnic Institute $(\mathrm{N}=36)$ & 6.60 & 1.02 \\
\hline University of Texas - Austin $(\mathrm{N}=47)$ & 7.29 & 1.29 \\
\hline
\end{tabular}

1) Answer categories ranged from $0=$ "strongly disagree" to $9=$ "strongly agree"

To test which institutions' averages were statistically significant for module 6 , we conducted a pair wise comparison analysis. None of the institutions' averages differed significantly from each other, however the difference between PSU and UT- Austin approached significance $(p=.060)$.

There were no other significant differences for students at the different institutions on the other modules.

\section{Effects of year-standing}

The item modules measure constructs such as self-beliefs and coping skills (see Figure 1). A higher score on any module indicates the student has "more" of this skill (e.g. better coping skills). Because Women in Engineering programs are designed to cumulatively positively impact these and other skills and factors through their programmatic offerings, we would hope to see that overall, Women in Engineering student participants' scores should improve the further they are in their education and the more they have participated in WIE activities. This would mean that these students with a higher year standing and more participation in WIE activities should score higher on modules than other students. The associated research questions are as follows.

2. Do students with different year-standings answer the module items differently across all institutions?

3. At each institution, do students with different year-standings answer the module items differently?

For question two, we found that students with different year-standings from all institutions answered the items significantly differently for module 4 -- confidence in doing well in engineering major $(F(3,175)=3.13, p<.05)$, module 5 -- confidence in being able to cope with difficulties $(F(3,175)=2.65, p<.05)$, and module 6 -- expectation that math is important for career and self worth $(F(3,175)=4.94, p<.01)$. Tables 3,4 and 5 show the pertinent descriptive statistics broken down by class standing for each of these modules. The higher means indicate a higher agreement with the statement explored.

Table 3: Averages and standard deviations for module 4: "Confidence in doing well in engineering major."

\begin{tabular}{|l|c|c|}
\hline Year standing & Mean $^{1)}$ & SD \\
\hline First year $(\mathrm{N}=55)$ & 6.35 & 1.15 \\
\hline Second year $(\mathrm{N}=30)$ & 7.00 & .83 \\
\hline Third year $(\mathrm{N}=40)$ & 6.84 & 1.19 \\
\hline Fourth / fifth year $(\mathrm{N}=50)$ & 6.90 & 1.19 \\
\hline
\end{tabular}

1) Answer categories ranged from $0=$ "not at all confident" to $8=$ "completely confident" 
Table 4: Averages and standard deviations for module 5: "Confidence in being able to cope with difficulties."

\begin{tabular}{|l|c|c|}
\hline Year standing & Mean $^{1)}$ & SD \\
\hline First year $(\mathrm{N}=55)$ & 6.15 & 1.11 \\
\hline Second year $(\mathrm{N}=30)$ & 6.33 & 1.28 \\
\hline Third year $(\mathrm{N}=40)$ & 6.34 & .98 \\
\hline Fourth / fifth year $(\mathrm{N}=50)$ & 6.73 & .95 \\
\hline
\end{tabular}

1) Answer categories ranged from $0=$ "not at all confident" to $8=$ "completely confident"

Table 5: Averages and standard deviations for module 6: "Expectation that math is important for career and self worth."

\begin{tabular}{|l|c|c|}
\hline Year standing & Mean $^{1)}$ & SD \\
\hline First year $(\mathrm{N}=55)$ & 7.05 & 1.32 \\
\hline Second year $(\mathrm{N}=30)$ & 7.44 & 1.38 \\
\hline Third year $(\mathrm{N}=40)$ & 6.00 & 2.22 \\
\hline Fourth / fifth year $(\mathrm{N}=50)$ & 6.75 & 1.68 \\
\hline
\end{tabular}

1) Answer categories ranged from $0=$ "strongly disagree" to $9=$ "strongly agree"

- For module four, pair wise comparison showed that none of the means for the different class standings differed statistically significantly, but the difference between first year students and second year students approached significance $(p=.075)$ as well as the difference between first year students and fourth / fifth year students $(p=.086)$.

- For module five, pair wise comparisons showed that first year students differed significantly from fourth / fifth year students (mean $=6.15$ versus mean $=6.73, p<.05$ ).

- For module six, pair wise comparisons showed that third year students differed significantly from first year students $(\mathrm{p}<.05)$ and from second year students $(\mathrm{p}<.01)$, with third year students scoring lower $($ mean $=6.00)$ than either first or second year students (means 7.05 and 7.44 , respectively).

The third research question examines differences by year standing at each individual institution. At Penn State, we found statistically significant differences among students of different yearstandings for modules six $(F(3,65)=3.99, p<.05)$ and nine $(F(3,65)=2.95, p<.05)$; see tables 6 and 7 for the means and standard deviations.

Table 6: Averages and standard deviations for module 6: "Expectation that math is important for career and self worth."

\begin{tabular}{|l|c|c|}
\hline Year standing & Mean $^{1)}$ & SD \\
\hline First year $(\mathrm{N}=21)$ & 6.68 & 1.40 \\
\hline Second year $(\mathrm{N}=12)$ & 7.56 & 1.56 \\
\hline Third year $(\mathrm{N}=14)$ & 5.43 & 2.21 \\
\hline Fourth / fifth year $(\mathrm{N}=19)$ & 6.14 & 1.44 \\
\hline
\end{tabular}

1) Answer categories ranged from $0=$ "strongly disagree" to $9=$ "strongly agree" 
Table 7: Averages and standard deviations for module 9: "Expectation to be treated fairly in an engineering job and to feel part of the group."

\begin{tabular}{|l|c|c|}
\hline Year standing & Mean $^{1)}$ & SD \\
\hline First year $(\mathrm{N}=21)$ & 6.90 & 1.10 \\
\hline Second year $(\mathrm{N}=12)$ & 8.17 & .85 \\
\hline Third year $(\mathrm{N}=14)$ & 6.86 & 2.30 \\
\hline Fourth / fifth year $(\mathrm{N}=19)$ & 7.81 & 1.40 \\
\hline
\end{tabular}

1) Answer categories ranged from $0=$ "strongly disagree" to $9=$ "strongly agree"

For module six, at PSU, pair wise comparisons showed a significant difference $(p<.01)$ between second $($ mean $=7.56)$ and third year students $($ mean $=5.43)$. There were no significant pair wise differences for module nine.

At UT- Austin, we found statistically significant differences among students of different yearstandings for modules two $(F(3,46)=1.31, p<.05)$, four $(F(3,46)=5.65, p<.05)$, six $(F(3,46)$ $=8.75, p<.05)$ and seven $(F(3,46)=5.35, p<.05)$; see tables $8,9,10$ and 11 for averages and standard deviations.

Table 8: Averages and standard deviations for module 2: "Confidence in personal success in engineering curriculum."

\begin{tabular}{|l|c|c|}
\hline Year standing & Mean $^{1)}$ & SD \\
\hline First year $(\mathrm{N}=15)$ & 2.73 & .89 \\
\hline Second year $(\mathrm{N}=8)$ & 3.48 & .43 \\
\hline Third year $(\mathrm{N}=12)$ & 3.28 & .36 \\
\hline Fourth / fifth year $(\mathrm{N}=11)$ & 2.87 & .45 \\
\hline
\end{tabular}

1) Answer categories ranged from $0=$ "strongly disagree" to $4=$ "strongly agree"

Table 9: Averages and standard deviations for module 4: "Confidence in doing well in engineering major."

\begin{tabular}{|l|c|c|}
\hline Year standing & Mean $^{1)}$ & SD \\
\hline First year $(\mathrm{N}=15)$ & 6.06 & 1.45 \\
\hline Second year $(\mathrm{N}=8)$ & 7.73 & .48 \\
\hline Third year $(\mathrm{N}=12)$ & 7.07 & .81 \\
\hline Fourth / fifth year $(\mathrm{N}=11)$ & 6.50 & 1.40 \\
\hline
\end{tabular}

1) Answer categories ranged from $0=$ "not at all confident" to $8=$ "completely confident"

Table 10: Averages and standard deviations for module 6: "Expectation that math is important for career and self worth."

\begin{tabular}{|l|c|c|}
\hline Year standing & Mean $^{1)}$ & SD \\
\hline First year $(\mathrm{N}=15)$ & 7.27 & 1.20 \\
\hline Second year $(\mathrm{N}=8)$ & 8.00 & 1.01 \\
\hline Third year $(\mathrm{N}=12)$ & 6.11 & 2.24 \\
\hline Fourth / fifth year $(\mathrm{N}=11)$ & 8.00 & 1.00 \\
\hline
\end{tabular}

1) Answer categories ranged from $0=$ "strongly disagree" to $9=$ "strongly agree" 
Table 11: Averages and standard deviations for module 7: "Expectation that engineering degree will result in obtaining desired lifestyle \& job."

\begin{tabular}{|l|c|c|}
\hline Year standing & Mean $^{1)}$ & SD \\
\hline First year $(\mathrm{N}=15)$ & 7.10 & .95 \\
\hline Second year $(\mathrm{N}=8)$ & 8.16 & .65 \\
\hline Third year $(\mathrm{N}=12)$ & 7.13 & 1.19 \\
\hline Fourth / fifth year $(\mathrm{N}=11)$ & 6.30 & 1.84 \\
\hline
\end{tabular}

1) Answer categories ranged from $0=$ "strongly disagree" to $9=$ "strongly agree"

- For module two, pair wise comparisons showed that first year students $($ mean $=2.73)$ score significantly lower than second year students (mean $=3.48, p<.05$ ).

- Likewise, for module four, pair wise comparisons showed that first year students (mean $=$ $6.06)$ score significantly lower than second year students (mean $=7.73, p<.05$ ).

- For module six, pair wise comparisons found two separate significant differences. Year two students $($ mean $=8.00)$ differed significantly from year three students $($ mean $=6.11$, $p<.05)$ and year three students differed significantly from year four students (mean $=$ $8.00, p<.05)$.

- For module seven, pair wise comparisons found that second year students $($ mean $=8.16)$ scored higher than fourth / fifth year students (mean $=6.30, p<.05$ ).

No significant differences were found between students of different year standings at either Georgia Tech or RPI, however this may be due to the relatively small sample sizes for students in different classes at each of these institutions.

Discussion

There are several noteworthy results to discuss from this study.

1. Regarding research question 2-do students with different year-standings answer the module items differently across all institutions - we do not see in our cross-sectional data a consistent pattern of significant differences between students in the lower year standings and those in higher year standings for the modules of items. We expected to see that lower division students had lower mean scores than upper division students for the item modules rather than the consistent pattern shown.

2. The above-described "pattern" of results also occurred for research question 3 where we examined year standing differences at each institution.

3. Lastly, for research question 1 which examined whether module responses differed significantly at different institutions, we found such differences on only one of the nine modules (Module 6: Expectation that math is important for career and self worth.).

The first two points are most likely due to two factors; first, (and probably most pertinent) the fact that this data set is cross-sectional and not longitudinal, and secondly the relatively small number of data points we have for each year standing or grade level. Referring back to Table 1, one can see that there were 63, 34, 45 and 55 responses for first, second, third and fourth / fifth year students for all institutions combined. Even with this relatively small set of responses, we had hoped to see means that increased with year standing, as we had expected that in general, 
more advanced students would have developed more in terms of the factors measured by the modules. The means for all modules broken down by year standing are shown in Table 12 .

Table 12: Averages for all modules by year standing.

\begin{tabular}{|l|c|c|c|c|}
\hline & First Year & Second Year & Third Year & Fourth / Fifth Year \\
\hline Module 1 * & 3.70 & 3.59 & 3.47 & 3.62 \\
\hline Module 2* & 2.82 & 3.00 & 3.06 & 2.97 \\
\hline Module 3 $*$ & 2.61 & 2.59 & 2.63 & 2.61 \\
\hline Module 4 ** & 6.35 & 7.00 & 6.84 & 6.90 \\
\hline Module 5 ** & 6.15 & 6.33 & 6.34 & 6.73 \\
\hline Module 6 \& & 7.05 & 7.44 & 6.00 & 6.75 \\
\hline Module 7 \& & 7.19 & 7.54 & 6.92 & 6.85 \\
\hline Module 8 \& & 5.05 & 4.80 & 5.32 & 4.84 \\
\hline Module 9 \& & 7.21 & 7.93 & 7.13 & 7.31 \\
\hline
\end{tabular}

* Responses $0-4$

** Responses $0-8$

\& Responses 0 - 9

As the reader can observe, there is no discernable pattern to these means and they certainly do not, with the possible exceptions of modules 4 and 5 where they are relatively flat and rising respectively, show steadily increasing means with increasing year standing. This leads us to our first explanation - namely that these are cross-sectional data rather than longitudinal. Although it is not unreasonable to expect that, for instance, a group of first year students taken as a whole would have consistently lower mean module scores than a different group of third or fourth year students, it is a more feasible hypothesis that we would see such progress by following the mean scores a single cohort of women students from their first year through to matriculation.

Lastly we address the lack of significant differences between students' module responses at the different participating institutions (research question one). As reported in Table 2, we only found significant differences between institutions on a single module - module six which addresses students' expectations about the importance of math for their careers. Without further data it is difficult to provide a meaningful interpretation of this single significant difference between institutions. Even though our initial analysis uncovered this difference, the pair-wise comparison showed that there were no identifiable significant differences between the four institutions. The lowest average (from PSU) approached being significantly different from the highest average (UT-Austin) however this may simply be a phenomenon associated with these being the two schools were we had the largest response rates on the survey. Given that only one module of nine showed such a significant difference and further that no per school significant differences were found for this one module, it is more likely that our original hypothesis that the differences between the institutions would result in differing module scores was erroneous. Although more data is clearly needed to strongly support these inferences, it would appear that some combination of the following is true:

- Women students who study engineering are more alike than different, regardless of their institutional choices. This is supported by Adelman ${ }^{27}$ in his discussion of science and math preparation of women (and men) engineering students, and even 
more strongly from the WECE report which indicates that institutional variables bore no relationship to women engineering students' graduation rate ${ }^{4}$.

- Further, we may argue that engineering curricula, faculty and other factors that define the engineering college climate are similar at the institutions where we gathered data. If this is the case, and it is also the case that women engineering students share similar entry characteristics, then it would follow that they would respond in similar ways to items designed to ascertain their self-efficacy relative to factors that are pertinent to the study of engineering.

- The result may also be interpreted as providing support for the validity of this instrument. Specifically, the modules were designed to measure factors that are commonly experienced by women engineering students and are the result of both literature review efforts to pinpoint what may be encountered as barriers by women engineering students (e.g. perceived self-efficacy in math, ability to cope with "unfriendly" environmental factors) and needs assessments with participating directors to uncover their perceptions of barriers to women successfully studying engineering. The current results imply support for the instrument's validity in measuring factors that are relevant to women engineering students. These preliminary data show that the factors measured by the modules are consistently experienced by women engineering students regardless of the different institution they are attending ${ }^{4}$.

\section{Conclusions and Future Directions}

This paper has reported the preliminary results of a newly designed and validated instrument designed to measure different aspects of self-efficacy of women studying engineering. The instrument was designed based on prior research and theoretical foundations from social psychology theory ${ }^{2,3}$ regarding barriers women face in studying engineering, as well as from expert review from women in engineering directors and other personnel with expertise on the barriers women face in an undergraduate engineering curriculum.

Results of this first-time data collection using this instrument with women engineering students at four differing engineering programs show that:

- Women engineering students at these four differing institutions responded in similar ways on all but one of the nine modules of items that comprise the instrument (research question one). An interpretation of this result is that women studying engineering at the undergraduate level share many similar characteristics regardless of the institution where they are studying and that because of the similarity of our initial set of institutions, women responded in similar ways regardless of institution.

- Women engineering students did not consistently respond to the modules in significantly different ways based on their year standing. We had hypothesized that, for instance, first year women would have consistently lower scores on the factors measured by the modules than upper division students, however our results did not show this to be true at 
this time most likely due to the cross-sectional nature of these data and the limited number of respondents.

As mentioned in the discussion section, the preliminary nature of these results clearly calls for future work items to strengthen or redirect these findings. Future work will include:

- Collecting and analyzing more data from a wider variety of institutions and a larger number of women engineering students. As mentioned, the University of Louisville and the University of Arizona have both been recently added to the AWE grant. The addition of data from their women students as well as other institutions that are expressing interest in this instrument should provide the analysis team with a more varied data set.

- Collecting and analyzing longitudinal data. All data reported here are cross-sectional. Clearly the areas of inquiry for research questions 2 and 3 lend themselves to a longitudinal design and analysis. We anticipate that longitudinal data will become available during the $2004-2005$ timeframe.

- Collect more data at each institution. Once again, the small sample size at each institution definitely introduces a higher chance of statistical error in our results. Larger sample sizes from each institution (which are currently being collected and analyzed) will provide us with a clearer picture of how responses do or do not vary amongst institutions.

- Analyze student responses in conjunction with their level of participation in WIE activities. We hypothesize that if students are participating in effective WIE activities that are designed to address (even if indirectly) the factors measured by the item modules, that such students would show "higher" scores. The model and supporting tools for implementing this analysis are currently being designed. We anticipate that such analysis will be possible during the $2004-2005$ timeframe.

- Use the instrument to collect data from men students as well as women. We recognize that it is critical to be able to compare responses based on gender. However, because we designed the instrument to focus on barriers for women engineering students and also because the first data collection was in part designed to validate the self-efficacy instrument, we chose to limit this initial effort to women. Subsequent iterations will be used with men and women and we will re-analyze our items for reliability at that time.

Recall that the instrument used in this study is one product from the NSF-funded "Assessing Women in Engineering" project. The goal of this project is to provide easily usable tools for WIE directors so they may both gather valid assessment data about their activities and then use these data to make evaluation, program improvement and funding decisions regarding their activities. Further, with validated instruments that are available to all WIE directors nationwide, the women in engineering community will have data for comparisons between and among different institutions and programs nationwide. The results reported in this initial analysis together with the plans and actions already under way to strengthen and add to our current results provide a strong evidence that this instrument will be a useful tool for WIE directors to 1) track the progress of their students on important factors that impact the success of women studying engineering and 2) provide data essential for understanding the effectiveness of the activities being offered at each institution. 


\section{References}

1. Mannix, M. (2001). Getting it right. Prism, 10(7), 14 - 21.

2. Bandura, A. (1986). Social foundations of thought and action: a social cognitive theory. Englewood Cliffs, N.J.: Prentice-Hall.

3. Blaisdell, Stephanie (2000). Social cognitive theory predictors of entry into engineering majors for high school students. Arizona State University. Unpublished dissertation.

4. Goodman, I.F.; Cunningham, C.M.; Lachapelle, C.; Thompson, M.; Bittinger, K.; Brennan, R.T.; Delci,. M. (2002). "Final report of Women's Experiences in College Engineering (WECE) project", Goodman Research Group Inc., Cambridge, MA. Available online at www.grginc.com.

5. Marra, R.M. and Bogue, B. (2001). "Developing Exportable Assessment Instruments and Models for Women In Engineering Programs", NSF Award \# HRD-0120642. National Science Foundation Program for Gender Equity in Science, Mathematics, Engineering and Technology (Program Announcement NSF 01-6).

6. Cunningham, C. M., Thompson, M., Lachapelle, C. P., Goodman, I. F., \& Bittinger, K. C. (2000). Women's experiences in college engineering and support programs: Findings from the WECE project. Paper presented at the WEPAN 2000.

7. Heller, R. S., \& Martin, C. D. (1994). Attracting young minority women to engineering and science: Necessary characteristics for exemplary programs. IEEE Transactions on Education, 37(1), 8-12.

8. National Science Foundation(2001). Program for Gender Equity in Science, Mathematics, Engineering and Technology (Program Announcement NSF 01-6): National Science Foundation.

9. Thompson, M., Cunningham, C., Lachapelle, C., Bittinger, K., \& Goodman, I. (2001). The Women's Experiences in College Engineering Project: WIE Directors.: Goodman Research Group, Inc.

10. Brainard, S., \& Carlin, L. (1998). A six-year longitudinal study of undergraduate women in engineering and science. Journal of Engineering Education, 87(4), 369-375.

11 Muller, C. B., \& Pavone, M. L. (1997). Retaining undergraduate women in science, math, and engineering: A model program. Paper presented at the Frontiers in Education, Pittsburgh, PA.

12 Bogue, B., \& Marra, R. (2001). Informal survey of WIE Directors.: Penn State University.

13. Bandura, A. (1997). Self-Efficacy: The Exercise of Control. New York: W.H. Freeman and Company.

14. Chen, G., Gully, S., \& Eden, D. (2001). Validation of a new general self-efficacy scale. Organizational Research Methods, 4(1), 62-83.

15. Pajares, F. (in press). Gender differences in mathematics self-efficacy beliefs. In A. M. Gallagher \& J. Kaufman (Eds.), Mind the gap: Gender differences in mathematics. Boston, MA: Cambridge University Press.

16. Luzzo, D. A., Hasper, P., Albert, K. A., Bibby, M. A., \& Martinellin, E. A. (1999). Effects of self-efficacyenhancing interventions on the math/science self-efficacy and career interests, goals, and actions of career undecided college students. Journal of Counseling Psychology, 46(2), 233-243.

17. Lent, R., Brown, S. D., \& Larkin, K. (1986). Self-efficacy in the prediction of academic performance and perceived career options. Journal of Counseling Psychology, 33(3), 265-269.

18. Taylor, K., \& Betz, N. (1983). Applications of self-efficacy theory to the understanding and treatment of career indecision. Journal of Vocational Behavior, 22, 63-81.

19. Turner, S., \& Lapan, R. (2002). Career self-efficacy and perceptions of parent support in adolescent career development. The Career Development Quarterly, 51, 44-55.

20. Ancis, J. R., \& Phillips, S. D. (1996). Academic gender bias and women's behavioral agency self-efficacy. Journal of Counseling \& Development, 75(2), 131-137.

21. Betz, N.E., \& Hackett, G. (1981). The relationship of career-related self-efficacy expectations to perceived career options in college women and men. Journal of Counseling Psychology, 28(5), 399-410.

22. O'Hare, S. (1995). Freshmen women in engineering: Comparison of their backgrounds, abilities, values, and goals with science and humanities majors. Journal of Women and Minorities in Science and Engineering, 2, 3347.

23. Hawks, B. K., \& Spade, J. Z. (1998). Women and men engineering students: Anticipation of family and work roles. Journal of Engineering Education, 249-256.

25. Brainard, S.G. (1993). Student Ownership: The Key to Successful Intervention Programs. Initiatives, 55(3), 2330.

26. Jackson, L. A., Gardner, P. D., \& Sullivan, L. A. (1993). Engineering persistence: Past, present, and future factors and gender differences. Higher Education, 26, 227-246. 
27. Adelman (1998). Women and men of the engineering path: A model for analysis of undergraduate careers. Washington, D.C.: U.S. Department of Education and The National Institute for Science Education.

28. Shaefers, K. G. (1993). Women in engineering: factors affecting persistence and attrition in college majors. Unpublished Ph.D., Iowa State University, Iowa.

29. Schaefers, K., Epperson, D. L., \& Nauta, M. M. (1997). Women's career development: Can theoretically derived variables predict persistence in engineering majors? Journal of Counseling Psychology, 44(2), 173-183.

30. Bradburn, E. M. (1995). Engineering gender roles: A self-efficacy model of occupational choice and persistence. Cornell U, US, 1.

31. Zeldin, A., \& Pajares, F. (2000). Against the odds: Self-efficacy beliefs of women in mathematical, scientific, and technical careers. American Educational Research Journal, 37(1), 215-246.

\section{Acknowledgement}

Support for this research is comes from NSF Award \# 0120642.

\section{Biographical Information}

ROSE M. MARRA is an Assistant Professor in the School of information science and Learning Technologies at the University of Missouri. She is PI of the NSF-funded Assessing Women in Engineering Project. Her research interests include gender equity issues, the epistemological development of college students, and promoting meaningful learning in web-based environments.

CHERITH M. MOORE is the AWE Research Assistant at the University of Missouri. Her research interests include gender equity in education, and women's career development.

MIEKE SCHUURMAN is a Research Associate at Penn State. She is project coordinator and data analyst of AWE. Her research interests include gender equity, assessment, and cooperative education.

BARBARA BOGUE is Director of Women in Engineering and Research Associate at Penn State. She is co-PI of AWE. Her research interests include programming and retention of women in engineering, assessment, web-based delivery, gender and teams, women and media, and revolution. 